\title{
PREPRINT FROM
}

\section{LOS ALAMOS SCIENTIFIC LABORATORY of the University of California LOS ALAMOS • NEW MEXICO}

\author{
DIST URBANCE OF CAPACITIVE LIQUID LEVEL GAUGES \\ BY NUCLEAR RADIATION
}

By

Walter L. Willis

RELEASED FOR ANNOUNCEMENT

IN NUCIEAR SCIENCE ABE TUATS

LEGAL NOTICE

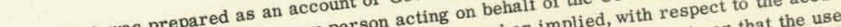
This report was prepission, nor any person expressed or implion, is report, or that the unge States, nor the Commaranty or representalingation contained in this report may not infne

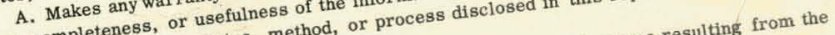
racy, completention, apparatus, method, or pros damages resuth

of any informed rights; or with respect to the use or, or on in this report. privately ownes any liabilities wethod, or process dhe Commission" include extent that B. Any information, apparating use of any the in the above, "Cersonssion, or employee of loyee of such contrant or contract As used in the commis the employment or co ployee or cone or contractor ol the cony information pursunt.

such employee or provides access to, ant with such contractor.

disseminates, or prov, or $\mathrm{h}$

with the 


\section{DISCLAIMER}

This report was prepared as an account of work sponsored by an agency of the United States Government. Neither the United States Government nor any agency Thereof, nor any of their employees, makes any warranty, express or implied, or assumes any legal liability or responsibility for the accuracy, completeness, or usefulness of any information, apparatus, product, or process disclosed, or represents that its use would not infringe privately owned rights. Reference herein to any specific commercial product, process, or service by trade name, trademark, manufacturer, or otherwise does not necessarily constitute or imply its endorsement, recommendation, or favoring by the United States Government or any agency thereof. The views and opinions of authors expressed herein do not necessarily state or reflect those of the United States Government or any agency thereof. 


\section{DISCLAIMER}

Portions of this document may be illegible in electronic image products. Images are produced from the best available original document. 


\title{
DISTURBANCE OF CAPACITIVE IIQUID LEVEL GAUGES BY NUCLEAR RADIATION*
}

\author{
Walter L. Willis
}

Los Alamos Scientific Laboratory, University of California

Los Alamos, New Mexico

\begin{abstract}
Liquid leve1 in the dewars at the Nuclear Rocket Development Site is monitored by temperature profiles, carbon resistor point sensors, and capacitance gauges which provide a continuous indication. The continuous nature of the capacitance gauges led to heavy reliance on the indication of level provided during reactor tests. Incorrect behavior of these gauges during tests in June of 1965 led to reactor damage.

The major difficulty with the capacitance gauge is the high impedance of the probe units. The excitation frequency and capacitance values yield impedances on the order of a megohm. If a low impedance system could be employed, radiation effects would become negligible. A solution to the problem appears to be a system called time domain reflectometry, or TDR. This system measures the characteristic impedance of a transmission line and detects the gas-1iquid interface by the sudden change in impedance. In this system the characteristic impedance is approximately 50 ohms. Tests indicate that radiation does not disturb this system.

It was concluded that capacitance gauges cannot be relied upon for future operations when the reactor is at high power levels. For these intervals two systems wi 11 be used. One is a set of fixed point sensors. The other will be TDR.
\end{abstract}

* Work performed under the auspices of the U. S. Atomic Energy Commission. 


\title{
DISTURBANCE OF CAPACITIVE LIQUID LEVEL GAUGES BY NUCLEAR RADIATION*
}

Walter L. Willis

\author{
Los Alamos Scientific Laboratory, University of California \\ Los Alamos, New Mexico
}

\begin{abstract}
INIRODUCTION
Liquid hydrogen storage capacity at the Nuclear Rocket Development Site (NRDS) in Nevada, as of tests conducted in 1965, consisted of two 28,000-ga1lon dewars and one 100,000-gallon dewar at Test Ce11 "A" and of two 50,000-gallon dewars at Test Ce11 "C". The liquid hydrogen serves as propellant and coolant for the nuclear rocket engine under development. Instrumentation in these dewars includes platinum resistance thermometers for temperature profiles, one-tenth watt carbon resistors for point level sensing, and capacitance gauges for continuous liquid level indications.

The continuous nature of the capacitance gauge indication led to primary reliance upon this system during run intervals. During tests in June of 1965 these gauges exhibited incorrect behavior, resulting in reactor damage.
\end{abstract}

\section{MALFUNCTION ANALYSIS}

The time required to shut down the reactor makes it mandatory to begin this procedure while sufficient liquid hydrogen remains to supply cooling during the entire interval. Figure 1 shows the liquid level indications recorded during the test in which damage occurred. The Dewar B indicator

* Work performed under the auspices of the U. S. Atomic Energy Commission. 
"hung up" at about $72 \%$ unti1 a liquid leve1 difference between Dewars $A$ and $B$ of about $20 \%$ was indicated. Later evidence indicates that liquid level in Dewar B continued to drop during the interval of constant indication; the result was the dewar going empty with an indication of about $20 \%$ liquid remaining.

Five capacitance gauge level indicators are in use at NRD. Four of these are of the same manufacture and this type was chosen for investigation. Examination of data from previous run intervals revealed unexplained anomalies, usually associated with high reactor power levels. The coincidence of malfunction and reactor power on otherwise we11-behaved"gauges led to suspicion of radiation effects. Figure 2, which is a simplified schematic of the system, shows three areas of possible interference; the indicator, the connecting cables, and the probe unit in the dewar. It should be noted that the probe is of the compensated type with level sensed by the tank unit and the signal modified by correction signals from the gas and liquid compensators. These latter are elements located at the ends of the tank unit.

A test chassis was fabricated which permitted testing an indicator and cabling with the probe unit simulated by variable capacitors. Resistive shunts were placed across all combinations of the interconnecting cabling. Shunts which were effectively across the capacitive elements were most disturbing. Shunting the tank unit with resistances of two megohms or less produced low reading errors while similar shunts across the compensators produced high readings. Combinations which made the indicator sluggish were obtainable. 
A series of radiation tests followed. Two samples of cable were irradiated in a Los Alamos reactor to dosages and rates far in excess of those experienced at NRDS while connected between the indicator and simulated probe. No detectable effect was produced.

The indicator was next irradiated while connected to the simulated probe and operating. Behavior was monitored by means of the transmitting potentiometer built into the unit. Again, no malfunction was evident, even at dose rates in excess of those measured at the test site.

The possibility of radiation incident upon the dewars affecting the probe unit was then examined, first by calculation, then by experiment. Figure 3 is a normalized radiation spectrum as measured near the dewars. This spectrum and information as to dewar geometry and materials was used in a computer program devised to calculate energy deposition in the liquid and gaseous hydrogen as a function of radius. ${ }^{1} \mathrm{~A}$ model was chosen in which the liquid was assumed to be a sphere of diameter equal to half the diameter of the dewar itself, centered within the dewar. While not physically realizable, this model simplified calculations. Figure 4 . shows the curves of energy deposition. ${ }^{2}$ Since the energy deposition in gas is only a small percentage of that in liquid, the step from the model to a real dewar is not disconcerting. It says, essentially, that most incident energy is given up in the first ten to fifteen centimeters of liquid. It should be noted that this is the energy associated with thermalizing the neutron flux. Two other mechantsms also exist. First, the thermal neutrons undergo $n-\gamma$ capture, releasing $\gamma$ radiation within the dewar. The energy involved is comparable to the thermalizing energy, but is distributed throughout the liquid 
due to the diffusion of neutrons and the fairly long path lengths of the $\gamma$ radiation. Second, a fairly high gamma flux is incident upon the dewar. This energy is also fairly well distributed throughout the dewar.

Figure 5 is a plot of energy deposition near the surface of the liquid hydrogen, obtained from Fig. 4 and the neutron flux measured on the dewars as given in Table $I$.

The problem is to convert these energy depositions to electrical conductivity in order to establish a relationship between radiation level and shunt resistance.

The electrical resistivity of cryogenic fluids was measured at Los Alamos and quantitative data pertaining to radiation was obtained for liquid deuterium, or heavy hydrogen. ${ }^{3}$ In this case, a tritium contamination depnsited energy at the rate of about $8 \mathrm{MeV} / \mathrm{cc} / \mathrm{scc}$. The clectrical resistivity measured was approximately $3 \times 10^{15} \mathrm{ohm}-\mathrm{cm}$.

In the case where conduction and capacitance fields are analogs, a simple relationship connects the two properties, that is, $R C=\epsilon \rho$, where $R$ is resistance in ohms, $C$ is capacitance in farads, $€$ is the dielectric constant of the medium, and $\rho$ is the resistivity. Several of these values are known or can be safely assumed. The tank unit capacity varies between 1430 and 1740 picofarad, $\epsilon$ is $\epsilon_{0} \epsilon_{r}$ or approximately $\left(10^{-3} / 36 \pi\right) \times 1.22$ farad/meter and an $R$ of $10^{6}$ ohms will badly disturb the gauge. For a disturbance at $75 \%$, let the tank unit capacity be about $1660 \times 10^{-12}$ farad. Thus, a resistivity of $1.54 \times 10^{8}$ ohm-meter or $1.5 \times 10^{10}$ ohm-cm will disturb the gauge. By scaling from the deuterium data, the energy input would have to be $1.6 \times 10^{6} \mathrm{MeV} / \mathrm{cc} / \mathrm{sec}$. Figure 5 shows that the energy input is actually 


\section{TABLE I}

Radiation for Dewar B, Test Cell C

\begin{tabular}{c|c|c|c}
\hline \multicolumn{2}{c}{ Gamma } \\
\hline Position & Total Dose, rad & Phoebus Dose, rad & Phoebus Rate, rad/sec \\
Top & $3.9 \times 10^{4}$ & $1.85 \times 10^{4}$ & 29.4 \\
Middle & $4.3 \times 10^{4}$ & $2.0 \times 10^{4}$ & 32.0 \\
Bot tom & $3.5 \times 10^{4}$ & $1.85 \times 10^{4}$ & 29.4
\end{tabular}

\begin{tabular}{c|c|c|c}
\hline \multicolumn{3}{c}{ Thermal Neutrons } \\
\hline Position & \multicolumn{4}{c}{ Total Dose, $\mathrm{n} / \mathrm{cm}^{2}$} & Phoebus Dose, $\mathrm{n} / \mathrm{cm}^{2}$ & Phoebus Rate, $\mathrm{n} / \mathrm{cm}^{2} / \mathrm{sec}$ \\
\hline Top & $3.3 \times 10^{13}$ & $1.5 \times 10^{13}$ & $2.4 \times 10^{10}$ \\
Middle & $3.6 \times 10^{13}$ & $1.7 \times 10^{13}$ & $2.65 \times 10^{10}$ \\
Bottom & $2.2 \times 10^{23}$ & $1.0 \times 10^{13}$ & $1.6 \times 10^{10}$
\end{tabular}

\begin{tabular}{c|c|c|c}
\hline & \multicolumn{4}{|c}{ Neutrons More Than $2.5 \mathrm{MeV}$} \\
\hline Position & Tota1 Dose, $\mathrm{n} / \mathrm{cm}^{2}$ & Phoebus Dose, $\mathrm{n} / \mathrm{cm}^{2}$ & Phoebus Rate $\mathrm{n} / \mathrm{cm}^{2} / \mathrm{sec}$ \\
\hline Top & $1.8 \times 10^{11}$ & $8.5 \times 10^{10}$ & $1.35 \times 10^{8}$ \\
Middle & $1.76 \times 10^{11}$ & $8.3 \times 10^{10}$ & $1.32 \times 10^{8}$ \\
Bottom & $9.6 \times 10^{10}$ & $4.5 \times 10^{10}$ & $7.2 \times 10^{7}$
\end{tabular}


$3.8 \times 10^{7} \mathrm{MeV} / \mathrm{cc} / \mathrm{sec}$ at the surface and decreases to the required value about $42 \mathrm{~cm}$ below the surface. If the energy input over the first foot of liquid is integrated, and consideration is given to the fact that this Is only a part of the probe length, a shunt of about 0.34 meg is obtained. When the $n-\gamma$ captures are considered, and the approximate $30 \%$ of the incident $\gamma$ flux that penetrates the dewar is added, shunts of even lower resistance are obtained.

One significant term has been neglected. Data presented in the referenced report show that conduction in gaseous hydrogen induced by radiation is comparable to the liquid phase. Admittedly, the energy deposition is much less. It turns out, however, that recombination rates are also proportionately lower, resulting in comparable electrical properties.

An alternative calculation can be performed, using data taken by $\mathrm{N}$. zessoules et al. 4 In this case, recombination rates were measured in iiquid hydrogen. About $2 \times 10^{-4}$ of all. ion pairs formed are available for conduction. Calculating the volume of the capacitance gauge, the corresponding energy deposition in $\mathrm{MeV} / \mathrm{sec}$ and using the value of 37 electron volts/ion pair, one can determine the electrons per second available for conduction. This current and the excitation voltage of the gauge also yield a resistance value comparable to that required for disturbance.

A probe was fabricated which was electrically equivalent to a partially filled probe but physically smallex. Flux maps of the Sandia Engineering Reactor were used to locate a position where radiation-induced conductivity in air would be equivalent to that calculated for liquid hydrogen in the dewars. The probe was inserted at this point and the reactor brought up . 
to power while the gauge behavior was monitored on a chart recorder. Figure 6 shows the data taken. The term S1 excursion refers to a switching function in which the indicator is made to run up scale on an internal standard and then reconnected to the probe to run back down scale at max- . imum tracking rate.

An increasing drift with rising radiation level to an error of about $15 \%$ is apparent. The very sluggish tracking on an S1 excursion at high radiation levels also indicates serious disturbance of the gauge.

An in-place check on these calculations was made during reactor tests at Test Cel1 "A" in March of 1966. A capacitance gauge was disabled for portions of two reactor tests and resistance measuring and recording equipment was connected to the gas compensator and the tank unit. Figure 7 is the record taken on the tank unit. The capacitance gauge wee in a cylindrical dewar and precise radiation level information near the dewars was not obtained. The calculations made for the spherical dewar do not apply exactly but the 250 kohms is quite near the 350 kohms calculated for the spherical case.

Figure 8 is the record taken on the gas compensator. The increase in resistance during full reactor power is attributed to the decreasing density of the hydrogen gas near the top of the dewar as. the liquid is replaced by warm pressurizing gas. This reduces the rate of energy absorption per unit volume.

A capacitance gauge could undoubtedly be designed to operate in the presence of radiation-induced shunting, perhaps by increasing the excitation frequency to lower the system impedance. 
Commercial equipment employing the principle of time domain reflectometry seems to offer an alternative. This equipment is designed to measure the characteristic impedance of transmission lines and present the measurement as a continuous function of length on an oscilloscope. Several dewars now have probes consisting of commercial 50-ohm coaxial transmission line. When the coaxial line is filled with liquid hydrogen the characteristic impedance decreases by several ohms. An electronic counter is used to measure the time interval characteristic of the distance between the impedance discontinuity at the liquid-gas interface and the bottom of the probe as presented by the oscilloscope display. Proper calibration yields a continuous linear indication of liquid level.

The system was tested in the Sandia Engineering Reactor with a short section of probe immersed in liquid nitrogen and located at a point where radiation-induced conductivity would exceed the test site values. No disturbance was noted. A more detailed description of this system is given elsewhere. 5

\section{CONCLUSIONS}

The existing capacitance gauges will be left in place for operations not involving reactors and as a cross check on the reflectometer systems. It is felt that capacitance gauges cannot be used for future reactor operations. Two systems, the reflectometer, and carbon point sensors, will be used for these interva1s. The degree of agreement between calculated and observed shunt resistances seems to support the data and methods used to calculate the effects of radiation in cryogens. 


\section{ACKNOWLEDGMENTS}

The assistance of Westinghouse Astronuclear Laboratory personnel in obtaining resịtance measurements during reactor tests at NRDS is gratefu1ly acknowledged. Sandia Corporation personnel are also to be thanked for their assistance in the use of reactor facilities for essential tests. 


\section{REFERENCES}

1. C. C. Cremer and R. E. Hunter, "Calculation of Neutron Heating in

a Phoebus Reactor Hydrogen Dewar", Office Memorandum W-4-1757, Los Alamos Scientific Laboratory, Ios Alamos, New Mexico, February 1966.

2. Ibid.

3. W. L. Willis, "The Electrical Conductivity of Some Cryogenic Fluids", IADC-7026, Master's Thesis, University of New Mexico, Albuquerque, New Mexico, March 1965.

4. Zessoules, N., et a1., 'Recombination and Mobility of Nuclear Radiation-Induced Ionfzation in Ifquid Hydrogen", Tracerlab, Inc., Waltham, Massachusetts, February 1962.

5. W. L. Willis and J. F. Taylor, "Time Domaln Reflectometry for Liquid Hydrogen Level Detect1on", IA-3474-MS, Unclassiffed Report, Los Alamos Scientific Laboratory, Ios Alamos, New Mexico, February 1966. 
Fig. I. capacitance gaUge llQuid LEVEL INDICATION

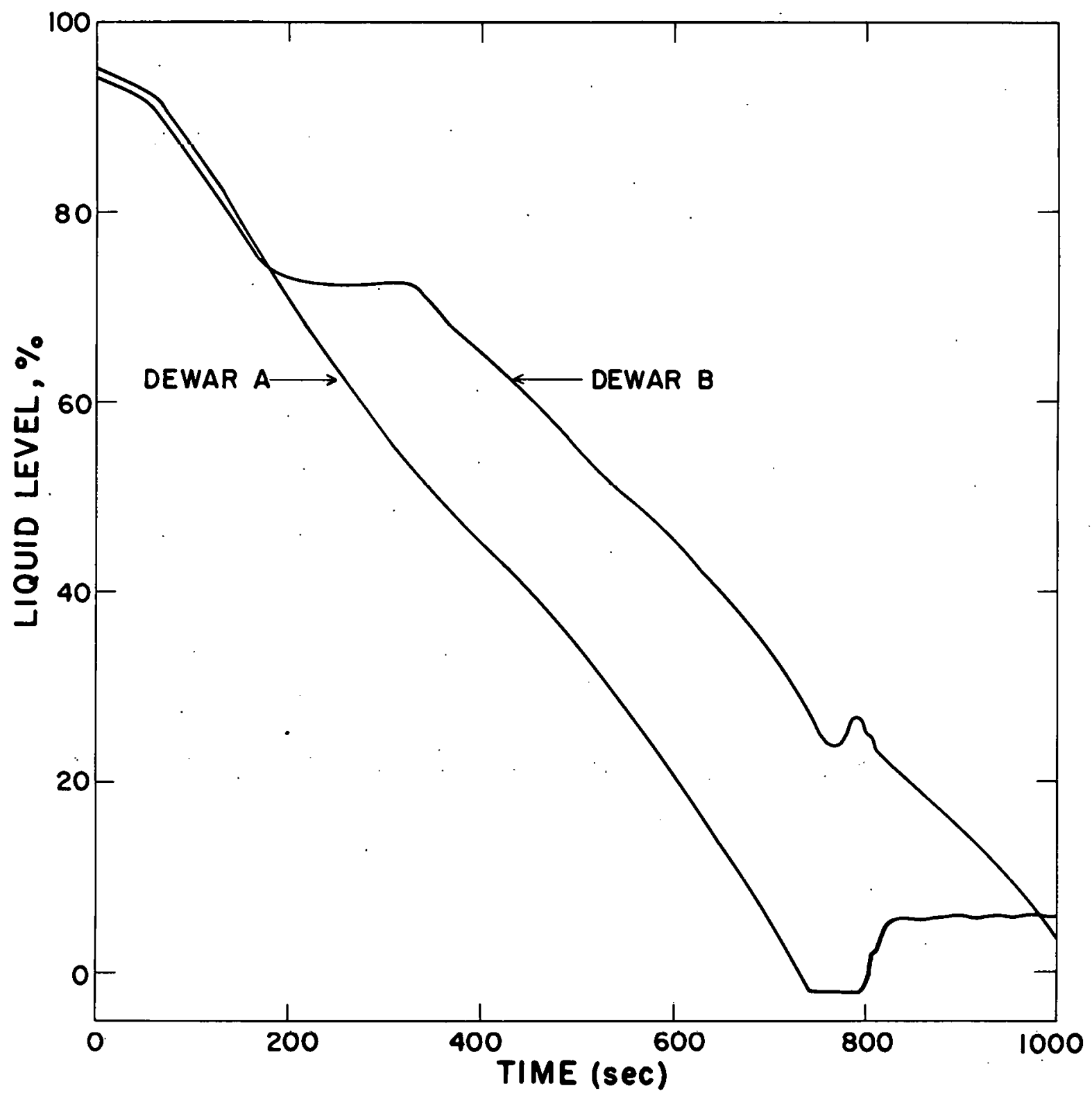


Fig. 2. CAPACITANCE GAUGE BLOCK DIAGRAM

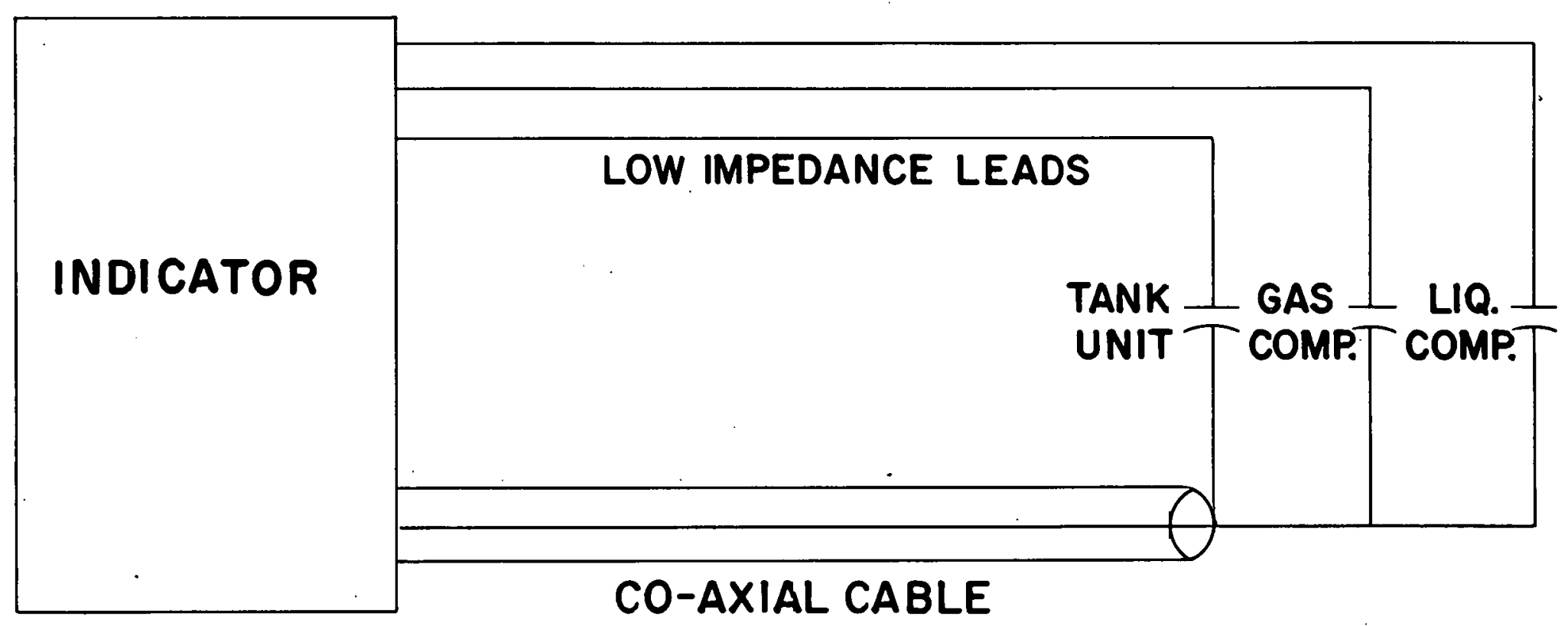


Fig. 3. NORMALIZED RADIATION SPECTRUM NEAR DEWARS

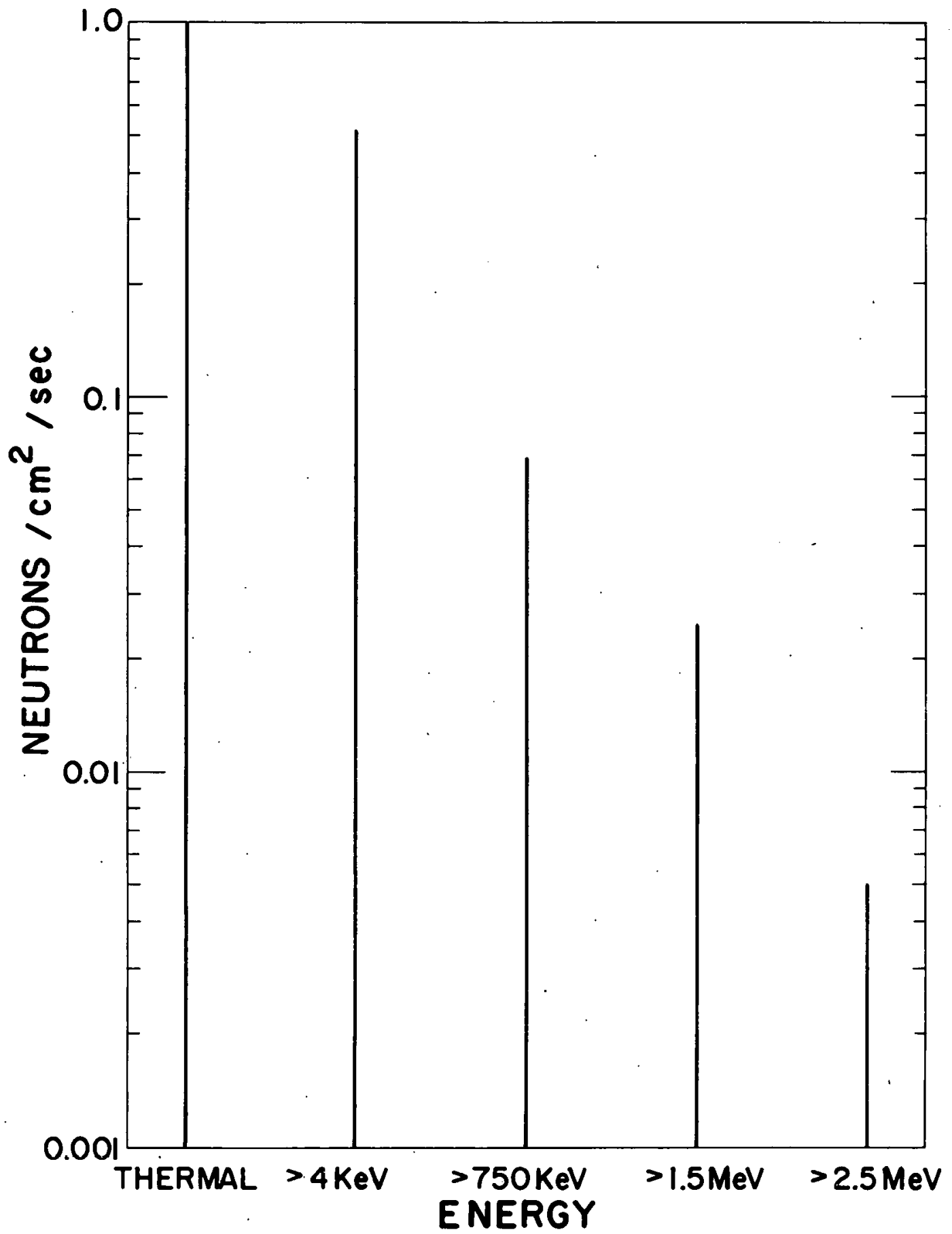


Fig. 4. INTEGRATED ENERGY ABSORBTION AS A FUNCTION OF POSITION FOR A NORMALIZED INCIDENT FLUX

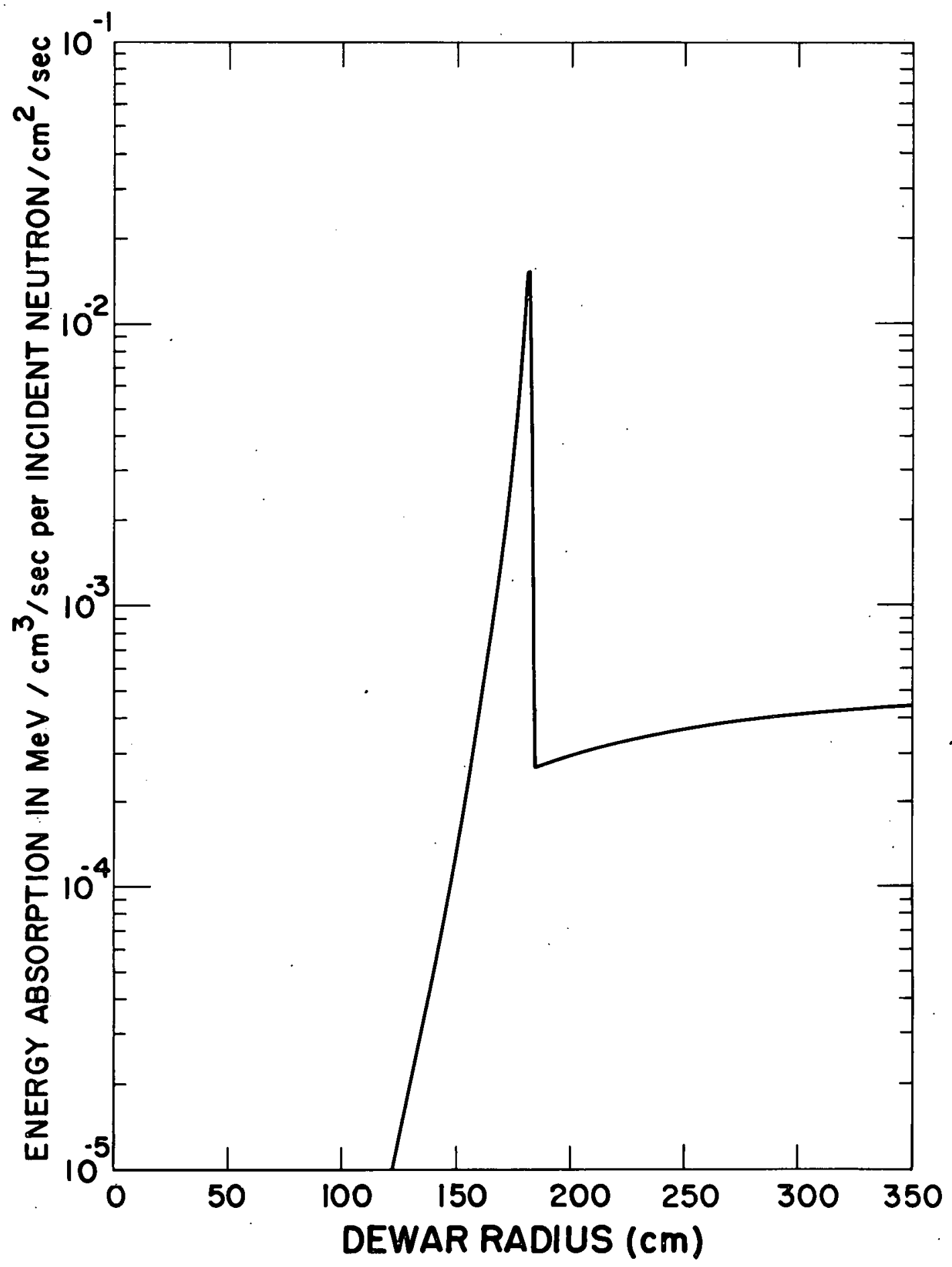


Fig.5. ENERGY DEPOSITION IN LIQUID HYDROGEN NEAR THE SURFACE

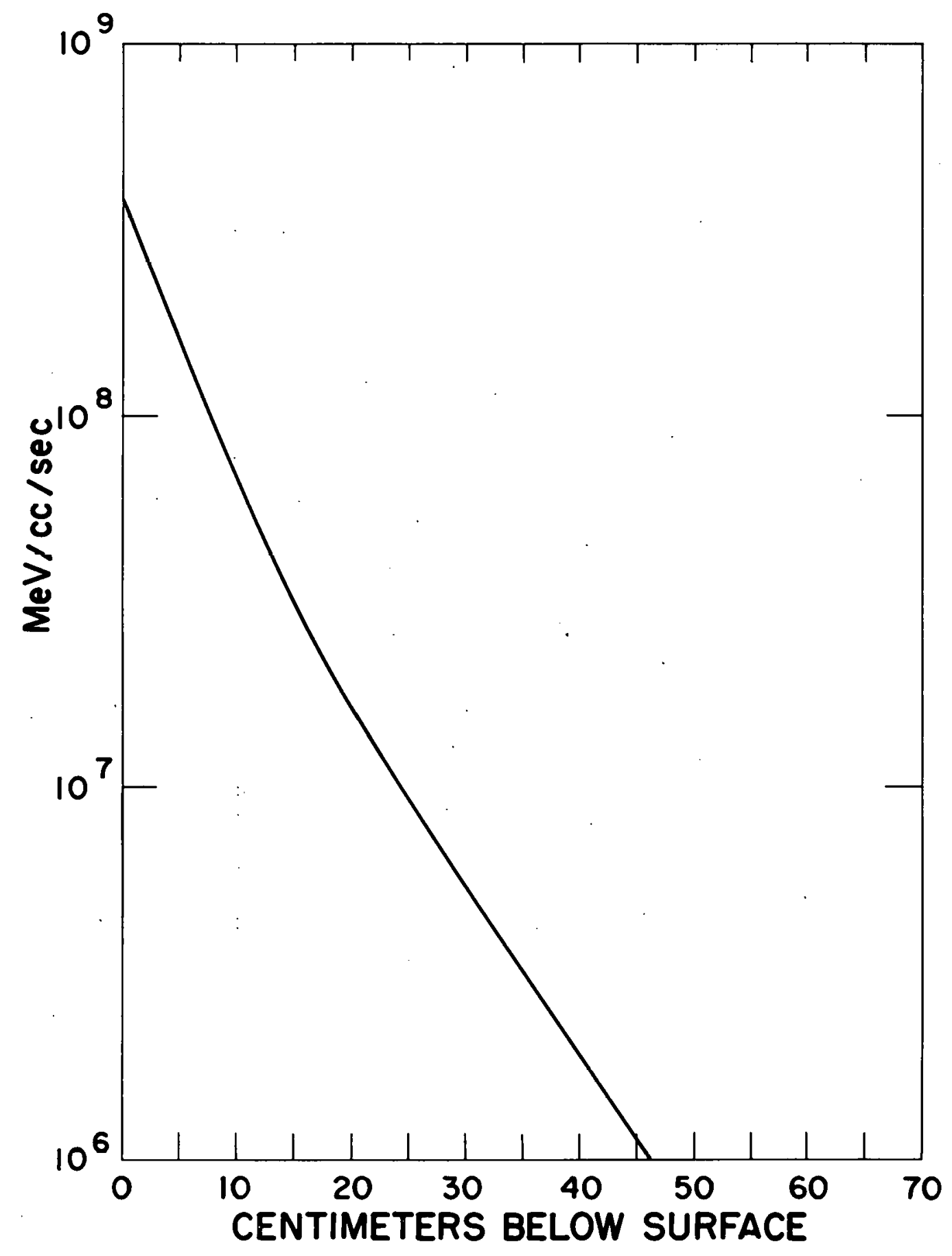


Fig. 6. CHART RECORD OF CAPACITANCE GAUGE BEHAVIOR DURING IRRADIATION

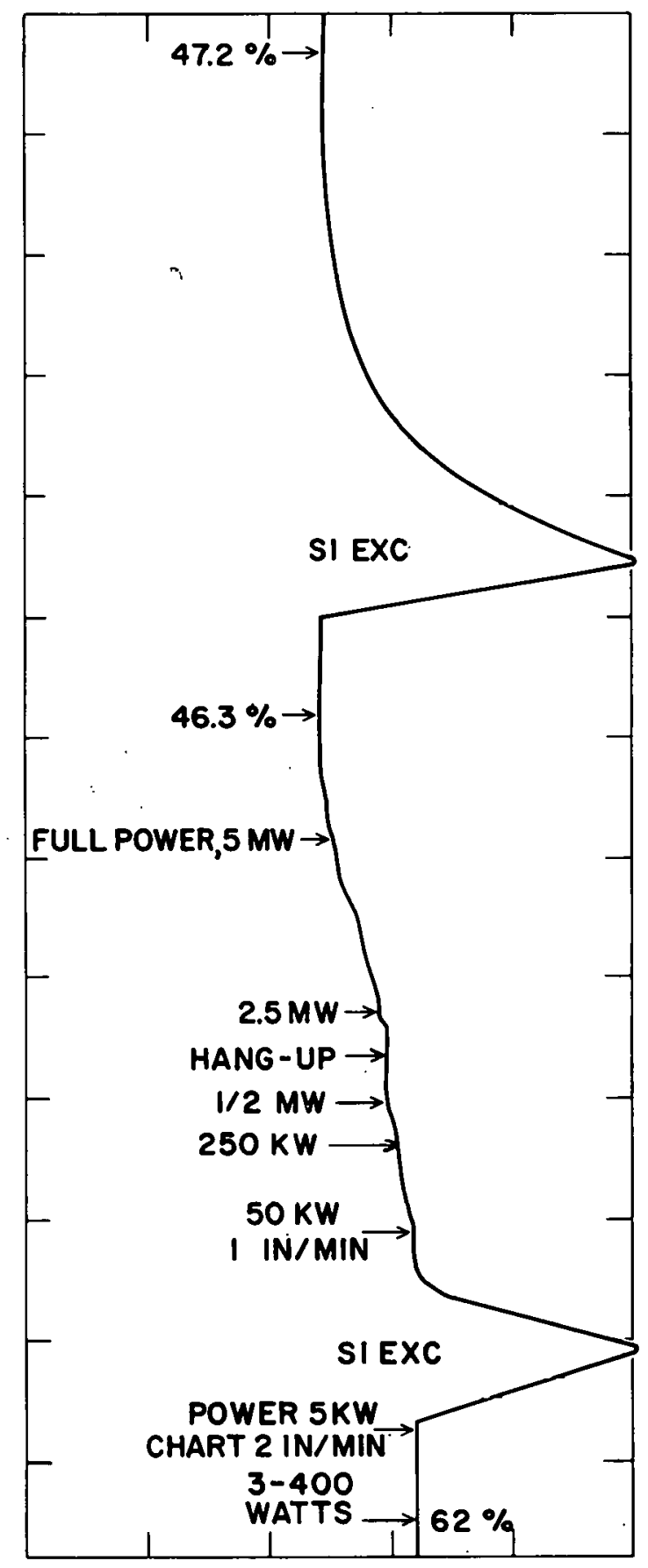


FIg. 7. RESISTANCE MEASURED ACROSS

TANK UNIT DURING REACTOR TEST

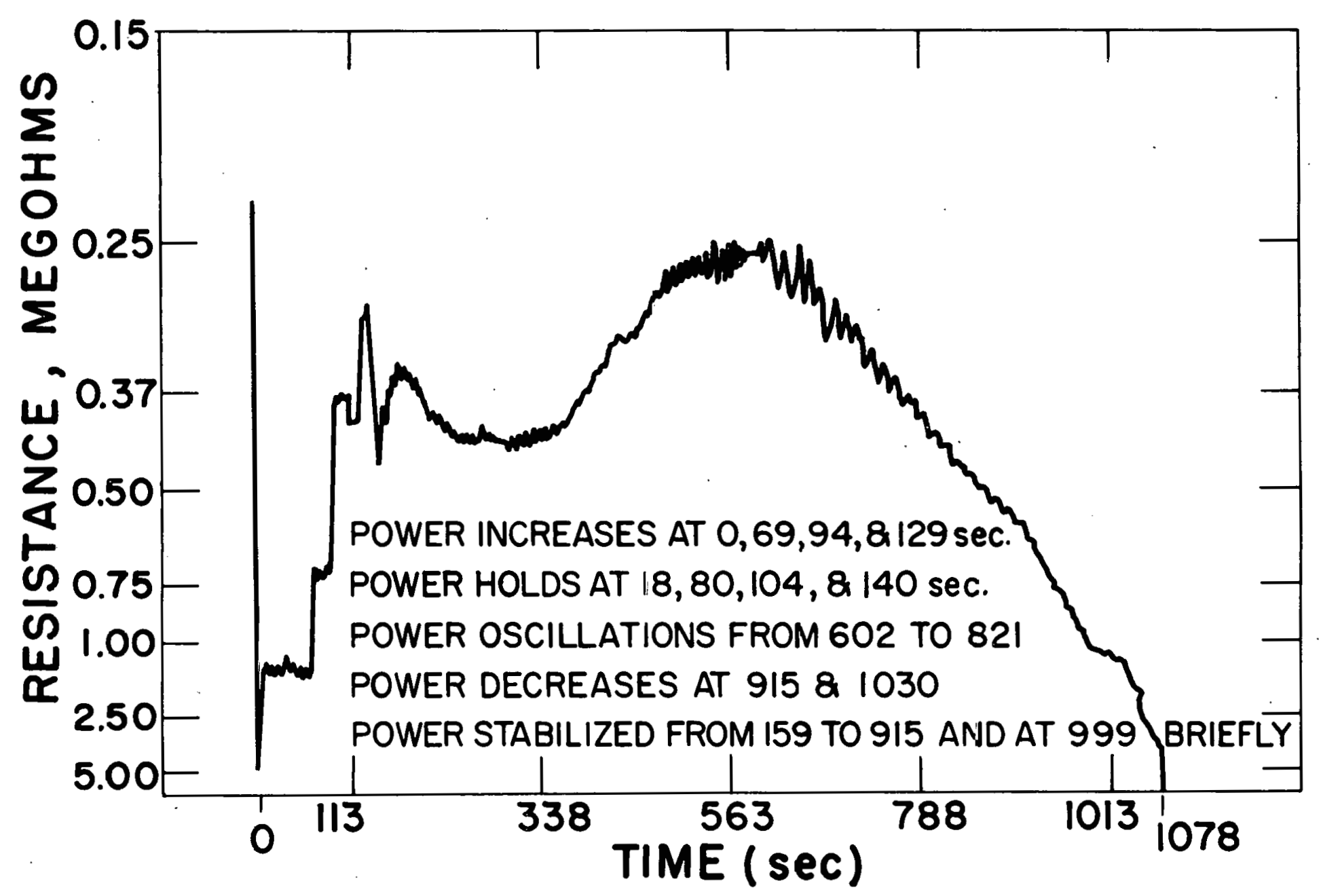


FIg. 8. RESISTANCE MEASURED ACROSS GAS COMP. DURING REACTOR TEST

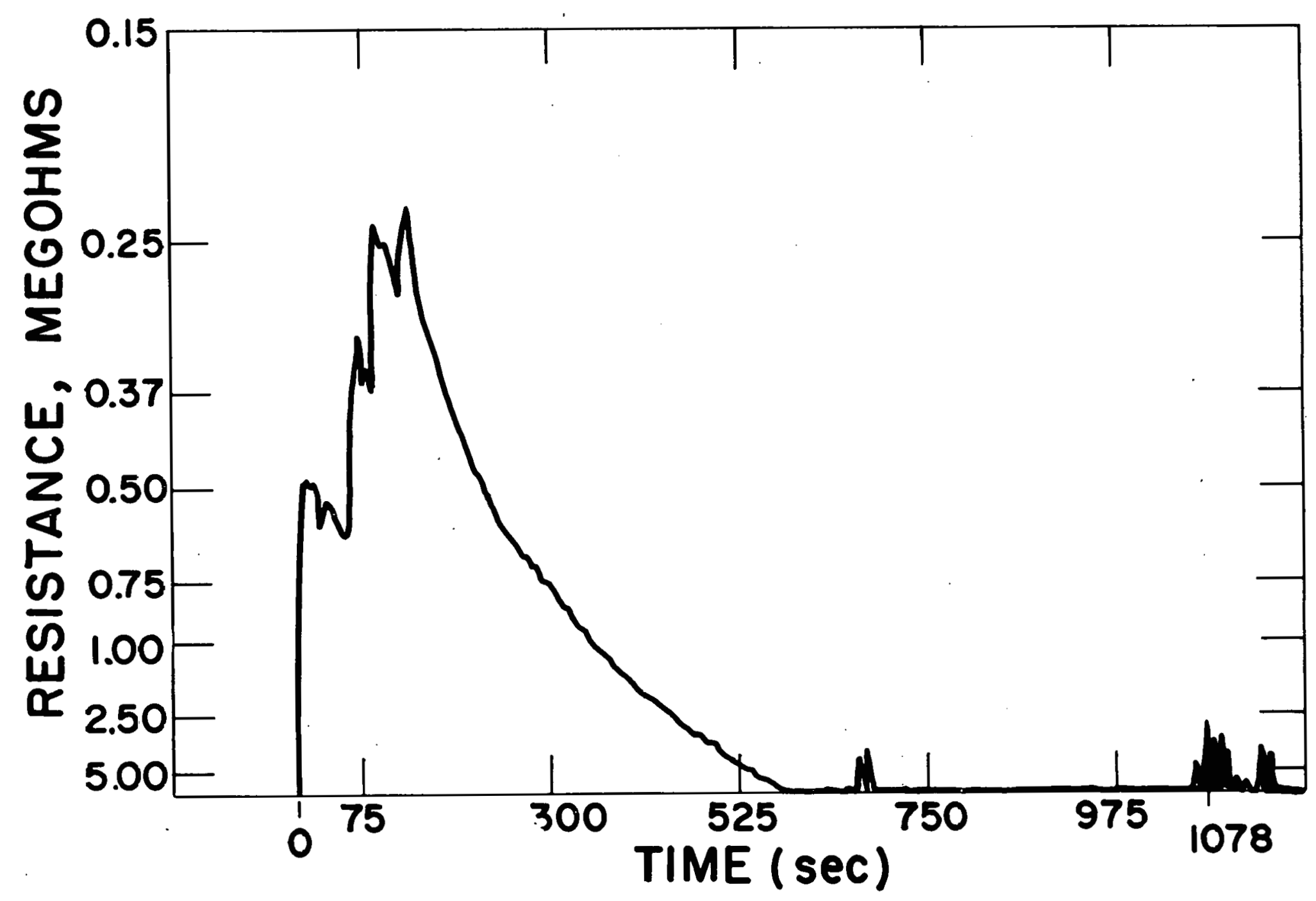

